\title{
The effects of climate sensitivity and carbon cycle interactions on mitigation policy stringency
}

\author{
Katherine Calvin • Ben Bond-Lamberty • \\ James Edmonds • Mohamad Hejazi • \\ Stephanie Waldhoff • Marshall Wise • Yuyu Zhou
}

Received: 15 February 2013 / Accepted: 1 December 2013 /Published online: 7 January 2014

(C) The Author(s) 2013. This article is published with open access at Springerlink.com

\begin{abstract}
Climate sensitivity and climate-carbon cycle feedbacks interact to determine how global carbon and energy cycles will change in the future. While the science of these connections is well documented, their economic implications are not well understood. Here we examine the effect of climate change on the carbon cycle, the uncertainty in climate outcomes inherent in any given policy target, and the economic implications. We examine three policy scenarios - a no policy "Reference" (REF) scenario, and two policies that limit total radiative forcing - with four climate sensitivities using a coupled integrated assessment model. Like previous work, we find that, within a given scenario, there is a wide range of temperature change and sea level rise depending on the realized climate sensitivity. We expand on this previous work to show that temperature-related feedbacks on the carbon cycle result in more mitigation required as climate sensitivity increases. Thus, achieving a particular radiative forcing target becomes increasingly expensive as climate sensitivity increases.
\end{abstract}

\section{Introduction}

Human activities produce a variety of greenhouse gas (GHG) emissions, including carbon dioxide $\left(\mathrm{CO}_{2}\right)$, methane $\left(\mathrm{CH}_{4}\right)$, and nitrous oxide $\left(\mathrm{N}_{2} \mathrm{O}\right)$. These gases, and their non-anthropogenic counterparts, accumulate in the atmosphere over time, altering the radiation balance and thus temperature of the Earth. The change in temperature for a given change in radiative forcing (RF) depends on climate sensitivity (CS). CS is a measure of the responsiveness of the Earth to changes in RF. CS is the equilibrium global mean temperature (GMT) rise associated with a doubling of

This article is part of a Special Issue on "A Multi-Model Framework to Achieve Consistent Evaluation of Climate Change Impacts in the United States" edited by Jeremy Martinich, John Reilly, Stephanie Waldhoff, Marcus Sarofim, and James McFarland.

Electronic supplementary material The online version of this article (doi:10.1007/s10584-013-1026-7) contains supplementary material, which is available to authorized users.

K. Calvin $(\bowtie) \cdot$ B. Bond-Lamberty $\cdot$ J. Edmonds $\cdot$ M. Hejazi $\cdot$ S. Waldhoff $\cdot$ M. Wise $\cdot$ Y. Zhou Joint Global Change Research Institute, College Park, MD 20740, USA

e-mail: katherine.calvin@pnnl.gov 
$\mathrm{CO}_{2}$-equivalent concentrations from pre-industrial levels (Hegerl and Zwiers 2007). Thus, if CS is $3{ }^{\circ} \mathrm{C}$, then doubling the $\mathrm{CO}_{2}$ concentration will result in an increase in GMT rise of $3{ }^{\circ} \mathrm{C} .{ }^{1} \mathrm{As}$ a result, $\mathrm{CS}$ is a vital element in determining the emissions limit required to reach a prescribed temperature goal (Edmonds and Smith 2006; Meinshausen et al. 2009). Specifically, a higher CS will result in a higher GMT change for a given level of emissions.

In addition to a linkage between emissions and temperature, there is also an established linkage between temperature and the carbon cycle (Cox et al. 2000; Friedlingstein et al. 2001, 2006; Randerson et al. 2009; Zeng et al. 2004). These studies find that warmer temperatures accelerate the global carbon cycle (Bond-Lamberty and Thomson 2010), causing an increase in microbial soil respiration. Additionally, while increases in $\mathrm{CO}_{2}$ concentrations lead to $\mathrm{CO}_{2}$ fertilization, or increased $\mathrm{CO}_{2}$ uptake, warmer temperatures may result in saturation of this $\mathrm{CO}_{2}$ uptake by vegetation. The net effect is a decrease in terrestrial carbon uptake as temperature rises, which results in higher atmospheric $\mathrm{CO}_{2}$ concentrations for the same level of $\mathrm{CO}_{2}$ emissions. The combination of these effects creates a positive feedback. Increasing $\mathrm{CS}$ results in higher temperatures for the same $\mathrm{CO}_{2}$ concentration levels. Higher temperatures result in higher $\mathrm{CO}_{2}$ concentration levels for the same level of emissions, and higher concentration levels lead to higher temperatures.

While the science of these connections is well documented, the economic implications of these phenomena are less established. Previous research has quantified the amount of mitigation required to keep temperatures below $2{ }^{\circ} \mathrm{C}$ as $\mathrm{CS}$ increases (Caldeira et al. 2003; Edmonds and Smith 2006) and under different assumptions about ocean heat uptake (Johansson 2011). However, these articles did not explore the role of CS on the carbon cycle. Other research has focused on carbon cycle uncertainty and its implications for the cost of stabilizing $\mathrm{CO}_{2}$ concentrations (Smith and Edmonds 2006), but this work did not link carbon cycle uncertainty to temperature. In this article, we combine the two lines of research and examine the effect of climate sensitivity on the carbon cycle from a mitigation perspective.

Many aspects of the earth system are uncertain, including climate sensitivity, $\mathrm{CO}_{2}$ fertilization, climate-carbon cycle feedbacks, aerosol forcing, and ocean heat diffusion (see (Tanaka et al. 2007) for a more complete discussion). In this analysis, we focus on one uncertainty, climate sensitivity, and its effects on the carbon cycle and mitigation policy. The Intergovernmental Panel on Climate Change (IPCC) states that the likely range for CS is between $2{ }^{\circ} \mathrm{C}$ and $4.5^{\circ} \mathrm{C}$, with the most likely estimate about $3{ }^{\circ} \mathrm{C}$, and values above $4.5^{\circ} \mathrm{C}$ still possible (Meehl et al. 2007). Here, we conduct a sensitivity analysis on this parameter and find that achieving a given RF target becomes increasingly expensive as CS increases due to climate feedbacks on the carbon cycle. However, we also find that the uncertainty associated with CS causes the scenarios to vary greatly with respect to the probability of more extreme changes in GMT. While the more stringent policy scenario has only a small effect on the GMT, compared to the more moderate policy target, at a $\mathrm{CS}$ of $3{ }^{\circ} \mathrm{C}$, it greatly increases the likelihood of remaining below $2{ }^{\circ} \mathrm{C}$ and not exceeding a GMT of $4{ }^{\circ} \mathrm{C}$.

The next section describes the methodology used in this paper, including a brief description of the Global Change Assessment Model (GCAM). Section 3 describes the results of the REF run. The effects of imposing a climate policy are detailed in Section 4. Section 5 discusses aspects related to risk and Section 6 concludes.

\footnotetext{
${ }^{1}$ In this paper, when we refer to $\mathrm{CS}$, we refer to equilibrium $\mathrm{CS}$, or the change in equilibrium temperature associated with a doubling of $\mathrm{CO}_{2}$ concentrations. The temperature rise numbers reported from the scenarios results, however, are transient temperature rise. None of these scenarios have reached their equilibrium temperature.
} 


\section{Methodology}

\subsection{The GCAM model}

The analysis undertaken in this paper uses the GCAM, Version 3.0 (Calvin et al. 2011; Clarke et al. 2007; Kim et al. 2006). GCAM is a global integrated assessment model that couples modules of the economy, energy system, agriculture system, land use, and the climate system in an internally consistent fashion. The world is subdivided into 14 geopolitical regions in the energy and economic systems and 151 regions in the agriculture and land-use systems. The model operates from 2005 to 2095 in 5-year increments. GCAM is a market-equilibrium model; that is, prices of all energy, agriculture, and forest products are adjusted until supply and demand are equilibrated. GCAM is a dynamic-recursive model, that is, decision-makers are myopic and future prices are not considered when choices are made.

The version of GCAM used for this analysis includes a representation of a water system with both supply and demand modules. The water supply module is a gridded $\left(0.5 \times 0.5^{\circ}\right)$ monthly water balance model. Using gridded monthly precipitation, temperature, and maximum soil water storage capacity (a function of land cover), it computes the amounts of evapotranspiration to the atmosphere, runoff, and soil moisture (Hejazi et al., under review). The water demand module includes six water demand components: agriculture (irrigation and livestock), primary and secondary energy production, manufacturing and mining, and the municipal sector. Agricultural water demand calculations are detailed, with derivations for 12 crop commodity classes at subregional scales (Chaturvedi et al., 2013). Industrial water demands are calculated for a wide range of energy technologies (Davies et al. 2013; Kyle et al. 2013), with the remainder of industrial water use assigned to manufacturing. Municipal water use is a function of GDP per capita, water price, and a technological change parameter (Hejazi et al., 2013).

GCAM computes emissions for 16 gases and short-lived species $\left(\mathrm{CO}_{2}, \mathrm{CH}_{4}, \mathrm{~N}_{2} \mathrm{O}\right.$, F-gases, $\mathrm{SO}_{2}, \mathrm{BC}, \mathrm{OC}, \mathrm{NO}_{\mathrm{x}}, \mathrm{CO}, \mathrm{NMVOCs}$ ) from a variety of human activities. GCAM computes GHG concentrations, RF, and climate-related variables with the Model for the Assessment of Greenhouse-gas Induced Climate Change (MAGICC) (Wigley and Raper 1992). MAGICC is a simple energy-balance model that includes coupled representations of gas-cycle and climate models. MAGICC has been calibrated to reproduce the results of more complex models. It allows the user to quickly analyze the effect of different projections of future anthropogenic emissions profiles on the carbon cycle, RF, GMT rise, and global mean sea level rise (SLR).

These analysis in this paper is part of the Climate Change Impacts and Risk Analysis (CIRA) project (Waldhoff et al. 2013, this issue), a project aiming to quantify climate change impacts within the United States. To ensure consistency across scenarios within the CIRA project, we have calibrated GCAM's regional GDP and population to MIT's EPPA model (Paltsev et al. 2013, this issue), described further in the Supplementary Material (SM).

\subsection{Scenarios}

The CIRA project combines three policy assumptions (No action (REF), Not-toExceed 4.5 W/m $\mathrm{m}^{2}$ (POL4.5), Not-to-Exceed $3.7 \mathrm{~W} / \mathrm{m}^{2}$ (POL3.7)) with four CS assumptions $\left(2{ }^{\circ} \mathrm{C}, 3{ }^{\circ} \mathrm{C}, 4.5{ }^{\circ} \mathrm{C}, 6{ }^{\circ} \mathrm{C}\right.$ ), resulting in 12 core scenarios (see (Waldhoff et al. 2013, this issue), for more details). For the REF scenarios, we only modify the CS parameter in the MAGICC component of GCAM. Thus, the four versions of the REF scenario have identical energy systems, agricultural systems, water demand, and emissions. They differ only in their GHG concentrations, RF, climate-related variables, and water supply. 
For the policy scenarios, we limit RF to its prescribed level by imposing a carbon price on all emissions, regardless of the source. Specifically, this carbon price applies not only to fossil fuel and industrial emissions, but also to land-use change emissions (see (Wise et al. 2009) for more information). We assume that all regions implement this carbon price beginning in 2015. The time-profile of the price path is chosen to reach the RF target in the most cost-effective manner. As a result, the price rises at the rate of interest until the target is reached. After that time, the carbon price is adjusted in each period to ensure that the target is not exceeded (Calvin et al. 2009). We compute carbon price paths for each of the four climate sensitivities and two RF targets. When varying the climate sensitivity, it is important to note that we adjust emissions to ensure the climate target is met, unlike the approach taken in the REF scenarios where emissions were held constant and climate responded.

\section{Business as usual scenario}

\section{$3.13{ }^{\circ} \mathrm{C}$ CS results}

The REF assesses the evolution of the economy, energy, agriculture, and climate system absent any climate policy. In such a world, future changes in energy, agricultural, land, and water demand are due to assumptions about socioeconomic conditions (Figure SM1), resource exhaustion, and technological progress. Global primary energy consumption rises in the REF Scenario, and the world remains dependent on fossil fuels to meet its energy needs (Fig. 1a). In the USA, primary energy consumption rises in the first half of the century and then stabilizes in the second half of the century (Fig. 1b), as increases in technological efficiency offset the increases in energy services demanded by a growing population. Like the world as a whole, the USA continues to rely heavily on fossil fuels throughout the century. ${ }^{2}$

Rising populations and increases in wealth result in greater demand for food over the course of the coming century, as GCAM assumes that people will shift to a more meat-intensive diet as incomes grow. These two effects, absent any other changes, would lead to an increase in land devoted to crop and pasture. However, the increases in agricultural productivity that are assumed in GCAM as a result of more mechanized agricultural production and future crop breeding efforts offset the increase in crop and pasture lands. The net effect is that cropland grows slightly between now and 2050 before declining (Fig. 1c). Pastureland remains virtually constant at a global level throughout the century. In the USA (Fig. 1d), land used for the production of food and fiber grows slightly in the near-term before stabilizing. Pastureland declines steadily, despite increases in animal production, to accommodate increasing bioenergy production.

On the water supply side, the amount of total runoff is projected to increase by about $12-13 \%$ both globally and in the USA by 2095 (Figure SM2). This change is attributed to the wet future climate associated with the IGSM-CAM model (Paltsev et al. 2013, this issue). Rising populations, higher demands, and technological shifts attribute to mixed results in total water demands. Total irrigation water demand for crops approximately doubles in the USA and triples in globally by 2095. These increases are due to the expansion of bioenergy and crop production to meet increasing demands. The non-irrigation sectors exhibit a similar trend of doubling globally by 2095 due to

\footnotetext{
${ }^{2}$ Note that there is the discontinuity in energy use, both globally and in the USA, in 2095. This discontinuity is a result of the exhaustion of conventional oil resources. To meet the continued demand for liquid fuels, the production of unconventional oil and coal-to-liquids increases in 2095. These liquid fuels are more energy and carbon-intensive than conventional oil, resulting in increased energy consumption (Fig. 1a, b) and increased $\mathrm{CO}_{2}$ emissions (Fig. 2a, b).
} 
increases in population, income, electricity and energy demand, especially in the developing world. In the USA, however, non-irrigation water demand decreases by about $40 \%$ by 2095 , primarily due to diminishing thermoelectric cooling water demand. This decrease is driven by shifts away from once-through cooling to more efficient cooling technologies. Therefore, under the REF, water demands are projected to increase by about $150 \%$ globally, and to stay roughly the same in the USA by 2095.

Because of the continued reliance on fossil fuels, both global and U.S. total anthropogenic $\mathrm{CO}_{2}$ emissions are dominated by energy-system emissions (Fig. 2a, b). Global $\mathrm{CO}_{2}$ emissions rise steadily throughout the century from $\sim 30 \mathrm{GtCO}_{2} / \mathrm{yr}$ in 2005 (cf. (Le Quere et al. 2009)) to $\sim 90 \mathrm{GtCO}_{2} / \mathrm{yr}$ in 2095. In the USA, $\mathrm{CO}_{2}$ emissions grow between 2005 and 2050 before roughly stabilizing. Land-use change (LUC) $\mathrm{CO}_{2}$ emissions grow modestly in the USA and decline slightly at the global level. However, in both cases, LUC emissions are a very minor component of total anthropogenic $\mathrm{CO}_{2}$ emissions.

The increase in $\mathrm{CO}_{2}$ emissions in the REF_CS3.0 Scenario results in a rise in $\mathrm{CO}_{2}$ concentrations from $380 \mathrm{ppmv}$ in 2005 to $883 \mathrm{ppmv}$ in 2095 . RF rises from $1.6 \mathrm{~W} / \mathrm{m}^{2}$ in 2005 to $7.2 \mathrm{~W} / \mathrm{m}^{2}$ in 2095 (Fig. 2c). This leads to an increase in GMT of $3.9^{\circ} \mathrm{C}$ above preindustrial in 2095 (Fig. 2d). Global SLR increases by $47 \mathrm{~cm}$ by 2095.

\subsection{The effect of CS on the carbon cycle}

Given the design of the REF scenario, varying the CS does not affect energy, agricultural, land use, or emissions (Fig. 3a). However, GMT increases with CS at a given level of RF. This increase in GMT in turn affects the carbon cycle. In particular, we observe a slight increase in ocean carbon uptake as the CS rises (Fig. 3b). However, this increased uptake is more than offset by a decline in terrestrial carbon uptake. ${ }^{3}$ Between climate sensitivities of $4.5^{\circ} \mathrm{C}$ to $6{ }^{\circ} \mathrm{C}$ the terrestrial system switches from a sink to a source of carbon. This decline in carbon uptake leads to a pronounced increase in the amount of carbon in the atmosphere. In $2095, \mathrm{CO}_{2}$ concentration levels range from 825 ppmv to 890 ppmv depending on CS.

Thus, changing CS creates a positive feedback loop, in which higher temperatures lead to more $\mathrm{CO}_{2}$ residing in the atmosphere, which results in different RF levels for the same emissions level (Fig. 2c) and even higher temperatures. GMT rise increases by a factor of two across the four REF runs. Much of this difference is attributable to changes in CS; however, some fraction of this is due to the temperature-carbon-cycle feedback. ${ }^{4}$ Even within a given emissions scenario, the uncertainty over CS creates a wide range of plausible changes to GMT in 2095. SLR is very sensitive to temperature increases, particularly because one cause of SLR is thermal expansion, so as RF increases, temperatures rise, and sea level also rises. The MAGICC results show a range in 2095 SLR for the REF scenario from $37 \mathrm{~cm}$ to $69 \mathrm{~cm}$ between $\mathrm{CS}$ of $2{ }^{\circ} \mathrm{C}$ and $6{ }^{\circ} \mathrm{C}$.

\footnotetext{
${ }^{3}$ LUC emissions are computed by the agriculture and land-use component of GCAM. However, the net terrestrial uptake is adjusted within MAGICC. This uptake accounts for $\mathrm{CO}_{2}$ fertilization and temperaturerelated effects of the carbon cycle.

${ }^{4}$ In a separate experiment, we turned off the climate-carbon cycle feedback in MAGICC and re-ran the REF with $\mathrm{CS}$ of $3{ }^{\circ} \mathrm{C}$ and $6{ }^{\circ} \mathrm{C}$. At $\mathrm{CS}$ of $3{ }^{\circ} \mathrm{C}$ and $6{ }^{\circ} \mathrm{C}, \mathrm{CO}_{2}$ concentrations are only 775 ppmv in 2095,70 ppmv and 115 ppmv less than the cases with climate feedbacks, respectively. In 2095 GMT rise is $0.25^{\circ} \mathrm{C}$ and $0.5^{\circ} \mathrm{C}$ higher with feedbacks than without for climate sensitivities of $3{ }^{\circ} \mathrm{C}$ and $6{ }^{\circ} \mathrm{C}$, respectively. These results are well within the range found in literature; (Friedlingstein et al. 2006), for example, finds that including the climate feedback results in an increase in $\mathrm{CO}_{2}$ concentrations between 20 and 200 ppmv and an increase in global mean temperature of between $0.1{ }^{\circ} \mathrm{C}$ and $1.5^{\circ} \mathrm{C}$. In eight of the eleven models included in this study, this effect is mainly attributed to changes in terrestrial carbon uptake.
} 

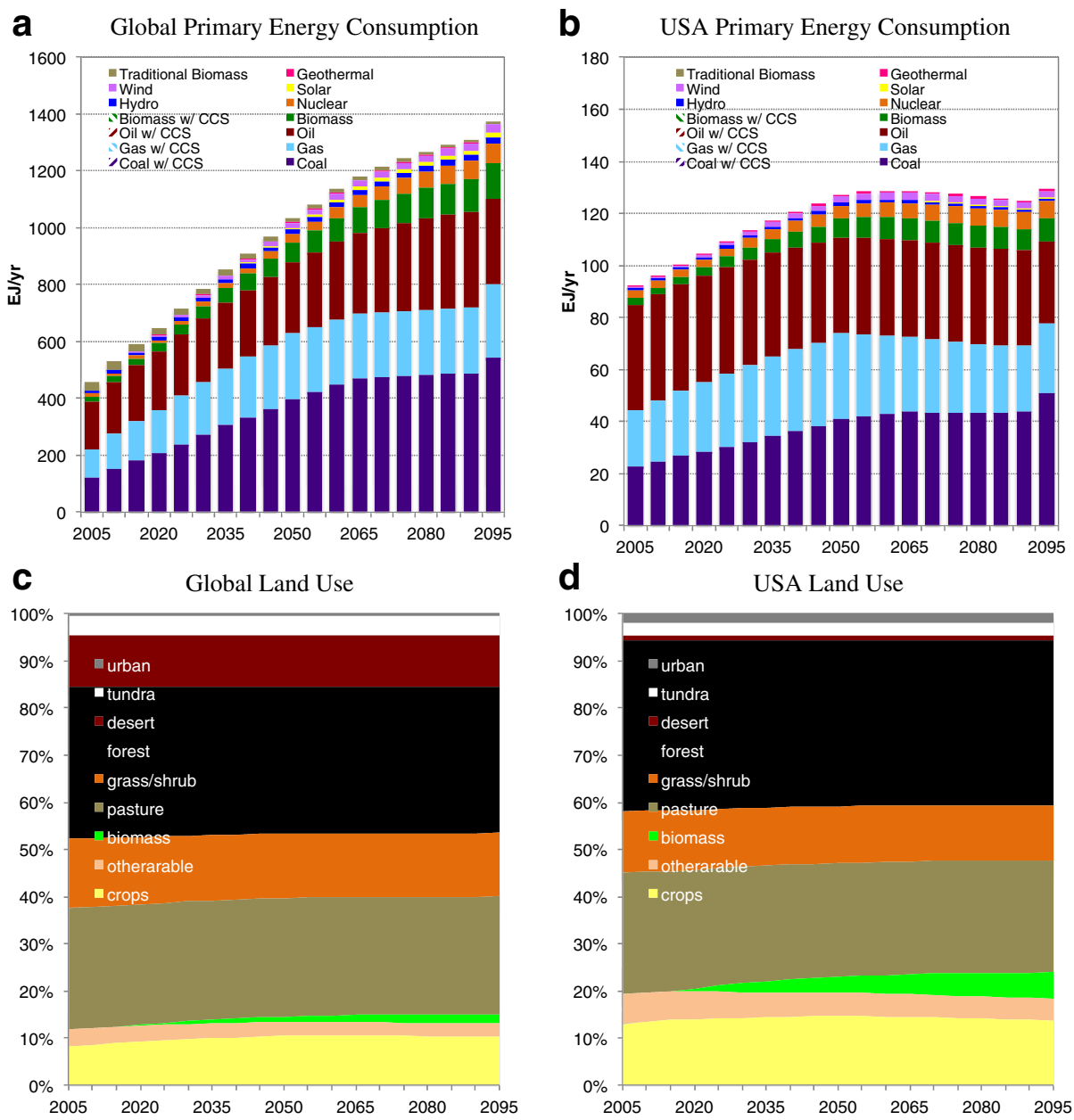

Fig. 1 Primary energy consumption and land use in the REF

\section{Policy results}

\section{$4.1 \mathrm{CS}$ of $3{ }^{\circ} \mathrm{C}$}

The imposition of a carbon price raises the costs of freely-emitting technologies in the energy system, rendering lower carbon technologies more attractive. As a result, primary energy consumption, both globally and in the USA, shifts towards nuclear, renewables, and $\mathrm{CO}_{2}$ capture and storage (CCS) technologies (Fig. 4a, b). In POL4.5, energy production from freely-emitting fossil fuel technologies are reduced from a peak of more than $700 \mathrm{EJ} / \mathrm{yr}$ in 2050 to below their 2005 values in 2095, whereas they grow continuously through the century in the REF scenario. In the USA, all coal is used in combination with CCS in 2095. Global nuclear power production grows by a factor of 16 over the coming century, biomass consumption increases by a factor of ten, and non-biomass renewables increase by a factor of eight between 2005 and 2095. 
In the terrestrial sphere, the imposition of a carbon price provides incentives for landowners to increase their terrestrial carbon stock. The increased demand for bioenergy in the energy system results in increased prices of bioenergy, which in turn influence land cover decisions. As a result of incentives to sequester carbon in the terrestrial system, global forest cover increases by $25 \%$ between now and 2095 (Fig. 4c) for the POL4.5 scenario. This compares with a slight decrease (4\%) forest cover in the REF scenario. POL3.7 has a slightly smaller increase in forests at $23 \%$ due to the increased demand for biomass production needed to meet the tighter RF target. Land devoted to the production of bioenergy accounts for $3 \%$ of global land and $9 \%$ of land in the USA in 2095 (Fig. 4c, d) in the POL4.5 scenario, compared with $2 \%$ and $6 \%$, respectively, in the REF.

In terms of water, climate policy leads to a decrease in total runoff and an increase in water demand both globally and in the USA (Fig. 5a-d). Although reduced temperatures lead to a reduction in evaporation, and thus, an increase in runoff, this feedback is offset by the decrease in precipitation leading to an overall decrease in total runoff as compared to the REF Scenario. On the demand side, higher biomass production and electricity use result in higher water demands than in the REF Scenario. Water stress (defined as the ratio of demand over supply) in the USA and globally (Fig. 5e, f) is affected by these changes in supply and demand. Water stress globally increases from about 10 to $22-28 \%$ in 2095 . This may pose formidable water stress challenges in the coming decades. In the USA, however, this ratio stays roughly around $17 \%$ throughout the century.

The carbon price required to limit RF to $4.5 \mathrm{~W} / \mathrm{m}^{2}$ rises exponentially between 2015 and 2095 (Fig. 6a). In the POL4.5 scenario, the price starts at $\$ 6 / \mathrm{tCO}_{2}$ in 2015 and reaches $\$ 195 / \mathrm{tCO}_{2}$ in $2095 .^{5}$ Total anthropogenic $\mathrm{CO}_{2}$ emissions decrease rapidly in the initial period, before rising again (Fig. 6b). Emissions then peak in 2050 at nearly $50 \mathrm{GtCO}_{2} / \mathrm{yr}$ before declining to less than one-third of their 2005 levels. The initial decline is due to the rapid expansion of forest cover globally (Fig. 4c) as a result of incentives to increase terrestrial carbon stocks. The potential for afforestation saturates soon after the policy is implemented. Emissions reductions that occur after that point are mostly due to mitigation efforts in the energy system.

With a CS of $3{ }^{\circ} \mathrm{C}$, climate policy reduces GMT rise in 2095 from $3.9{ }^{\circ} \mathrm{C}$ in the REF Scenario to $2.6{ }^{\circ} \mathrm{C}$ in the POL4.5 scenario and $2.2{ }^{\circ} \mathrm{C}$ in the POL3.7 scenario. SLR in 2095 is reduced from $47 \mathrm{~cm}$ in the REF to $36 \mathrm{~cm}$ in the POL4.5 scenario and $32 \mathrm{~cm}$ in the POL3.7 scenario.

\subsection{The effect of CS on mitigation}

In the policy cases, we prescribe a target RF value and allow emissions, carbon prices, energy use, water demand, and land cover to respond in order to meet the target. As described in Section 3.2, due to the climate feedback on the carbon cycle, varying the CS results in changes in these systems. However, unlike in the REF where we held emissions constant and observed changes in the carbon cycle, in the mitigation scenarios we allow the model to adjust emissions so that the climate target is met. As a result, we find that, to reach the same RF target with higher climate sensitivities, lower anthropogenic $\mathrm{CO}_{2}$ emissions (Figs. $6 \mathrm{~b}$ and $3 \mathrm{c}$ ) and higher carbon prices (Fig. 6a) are required. ${ }^{6}$

As in the REF, we see a decline in terrestrial carbon uptake as the CS increases (Fig. 3d). The model responds to this reduction in uptake by increasing mitigation of anthropogenic

\footnotetext{
${ }^{5}$ All prices are in 2005 USD.

${ }^{6}$ Note that high carbon prices do not necessarily imply high economic costs (see Luderer et al. 2012).
} 
emissions (Fig. 3c) to maintain roughly constant atmospheric $\mathrm{CO}_{2}$ concentrations (Fig. 3d). This requires additional effort as demonstrated by the change in carbon price. ${ }^{7}$ For both the POL 3.7 and POL 4.5 RF targets, the carbon price is $20+\%$ higher under a $6{ }^{\circ} \mathrm{C} \mathrm{CS}$ than under a $2{ }^{\circ} \mathrm{C} \mathrm{CS}$ in 2050 and $\sim 50 \%$ higher in 2095 (Fig. 6a).

The CIRA scenarios are designed to limit RF to prescribed levels with four different climate sensitivities. As discussed above, GMT change depends not only on the RF target, but also on the CS. The uncertainty around CS results in a wide range of GMT change at a given RF level. Thus, GMT rise could range from $1.9^{\circ} \mathrm{C}$ to $4.0^{\circ} \mathrm{C}$ in 2095 for a POL4.5 scenario (Fig. 6d) or $1.6{ }^{\circ} \mathrm{C}$ to $3.4{ }^{\circ} \mathrm{C}$ for the POL3.7 scenario. ${ }^{8}$

If instead we opted to constrain temperature rise to a specific level, the difference in mitigation effort across climate sensitivities would be larger than in the RF constraint scenarios. For example, limiting temperature rise to $2.6{ }^{\circ} \mathrm{C}$ (the 2095 warming level in a POL4.5_CS3.0) under a $6{ }^{\circ} \mathrm{C} \mathrm{CS}$ requires RF to kept below $2.6 \mathrm{~W} / \mathrm{m}^{2}$. In order to meet such a goal, global anthropogenic $\mathrm{CO}_{2}$ emissions would need to peak at $20 \mathrm{GtCO}_{2} / \mathrm{yr}$ in 2030 , as compared to a peak of $47 \mathrm{GtCO}_{2} / \mathrm{yr}$ in 2050 under a $3{ }^{\circ} \mathrm{C}$ CS. Such effort would require a carbon price through 2080 that is more than four times higher than that of the POL4.5_CS3.0 scenario. This change in peak emissions is consistent with (Caldeira et al. 2003; Edmonds and Smith 2006). ${ }^{9}$

In summary, the carbon price required to achieving a RF target increases with CS because tighter emissions limits are required to meet the same RF goal. In addition, for a given RF target, even when the emissions mitigation is adjusted for the level of CS, GMT will still increase with CS, a result consistent with previous literature. Restricting emissions to specific levels will not guarantee that a RF target will be met, nor does meeting a RF target guarantee a specific GMT change.

\section{Mitigating risk through mitigation}

For a risk-averse society, a thorough understanding of the risks associated with different future scenarios is essential to informed decision-making. This requires the evaluation of both the potential to achieve the desired GMT change and the likelihood of more extreme changes in the climate. Decisions that are made based on only the GMT change at the current "most likely" CS will fail to capture society's risk aversion to potentially catastrophic climate change. ${ }^{10}$

\footnotetext{
${ }^{7}$ In this article, we are using carbon price as an indicator of the cost of mitigation. The carbon price tracks most cost metrics in an idealized policy environment, which we assume here. In the context of non-ideal policies, the carbon price can become decoupled from the policy cost (see Bernstein et al. 2003 and Montgomery et al. 2003). ${ }^{8}$ Note that GMT rise in 2005 differs across the four climate sensitivities. In this experiment, we have only altered the CS parameters within MAGICC. In reality, several other parameters (e.g., aerosol indirect forcing) are correlated with CS, and should be adjusted simultaneously in order to replicate the observational record. The precise parameters and their values are uncertain, as is the observational record. Thus, for this paper, we have only adjusted CS. We did conduct an additional set of experiments where we adjusted CS and several additional parameters within MAGICC. These adjustments did not alter the findings reported in this paper. A more complete description of this experiment and its results are included in the SM.

${ }^{9}$ Note that this study uses a different target temperature and different climate sensitivities than the two previous studies. Thus, direct comparisons are difficult.

${ }^{10}$ The risks associated with climate change are dependent upon multiple uncertainties (see (Waldhoff et al. 2013, this issue) for a detailed discussion on sources of uncertainty in estimating the impacts and damages from climate change). This analysis examines the effects of uncertainty over global average temperature change only and the authors acknowledge this limitation.
} 

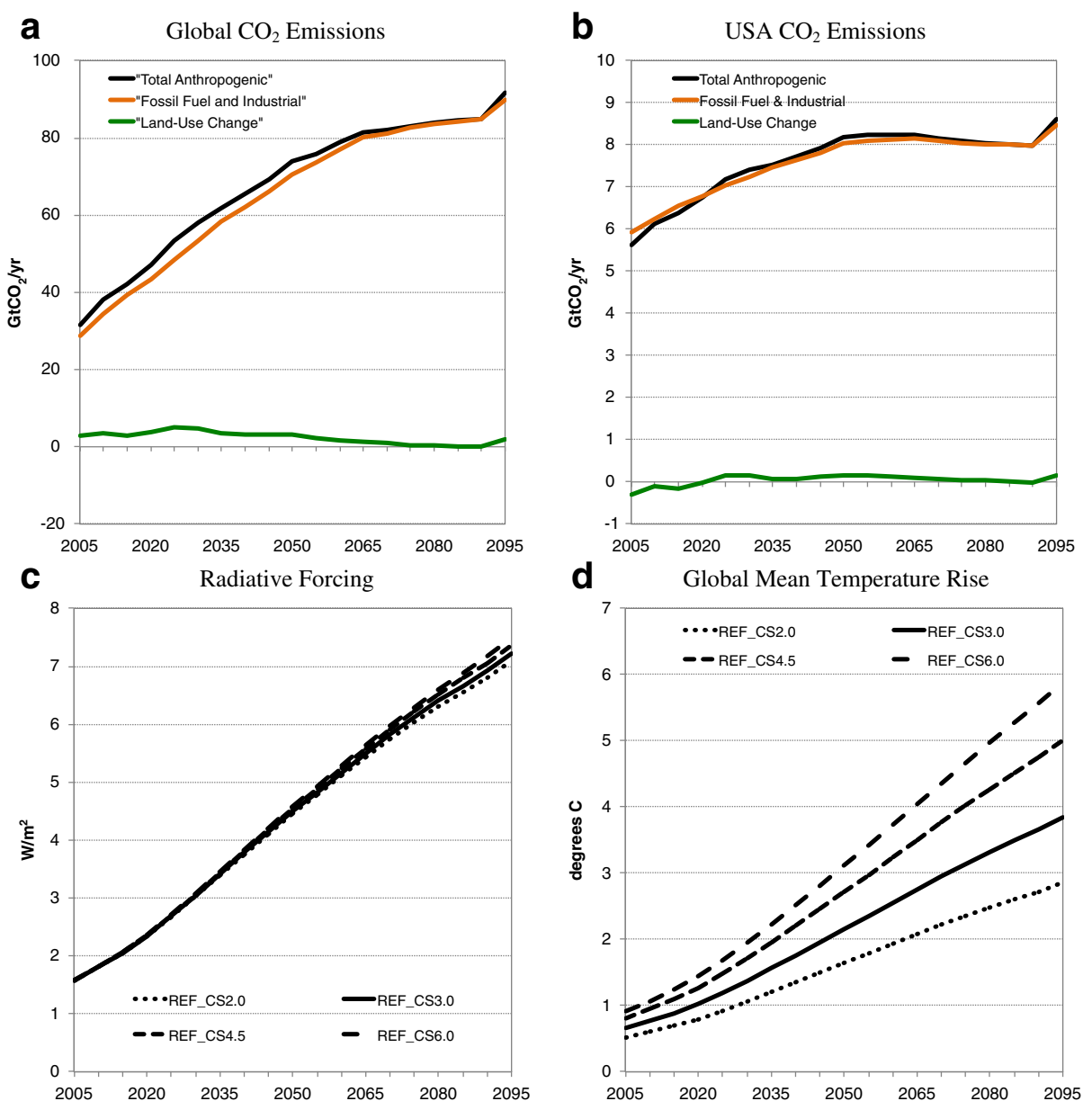

Fig. 2 Emissions, radiative forcing, and global mean temperature rise in the reference

The scenarios described in this paper show a significant level of uncertainty surrounding the level of climate change that will be realized with any specific RF or emissions reduction policy. When these three scenarios are analyzed at the current IPCC estimate of the "most likely" CS of $3{ }^{\circ} \mathrm{C}$ (IPCC 2007), the global average temperature changes in 2095 are $3.9{ }^{\circ} \mathrm{C}, 2.6{ }^{\circ} \mathrm{C}$, and $2.2{ }^{\circ} \mathrm{C}$, for the REF, POL4.5, and POL3.7 scenarios, respectively.

However, Fig. 7 shows the cumulative density functions for GMT in 2095 for each of the three scenarios and emphasizes the differences in the distribution of GMT across emission scenarios. By applying a an approximation of the probability distribution for climate sensitivity provided in (Roe and Baker 2007), ${ }^{11}$ we can examine

${ }^{11}$ This is the distribution over climate sensitivity used by the U.S. Government as implemented in the 2010 Social Cost of Carbon exercise. 
a

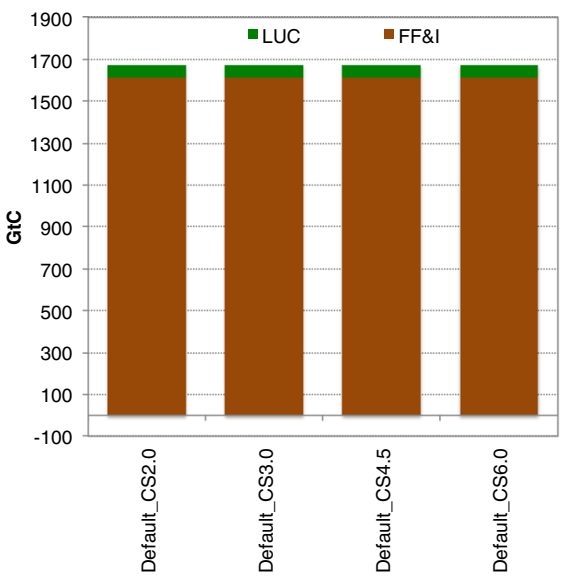

C Cumulative $\mathrm{CO}_{2}$ Emissions (POL4.5)

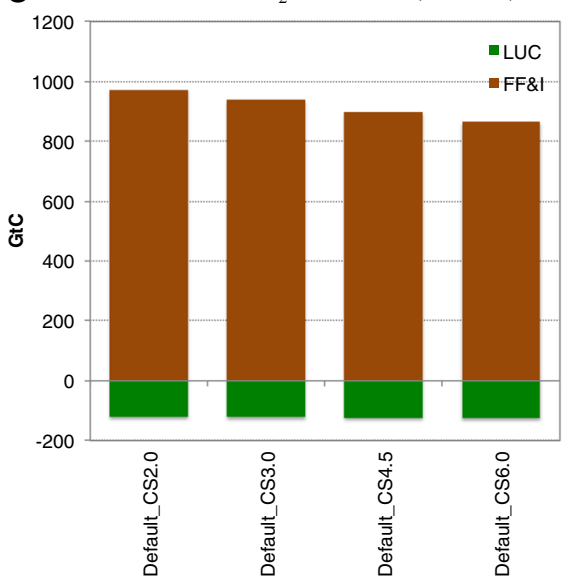

b Carbon Uptake and $\mathrm{CO}_{2}$ Concentration (REF)

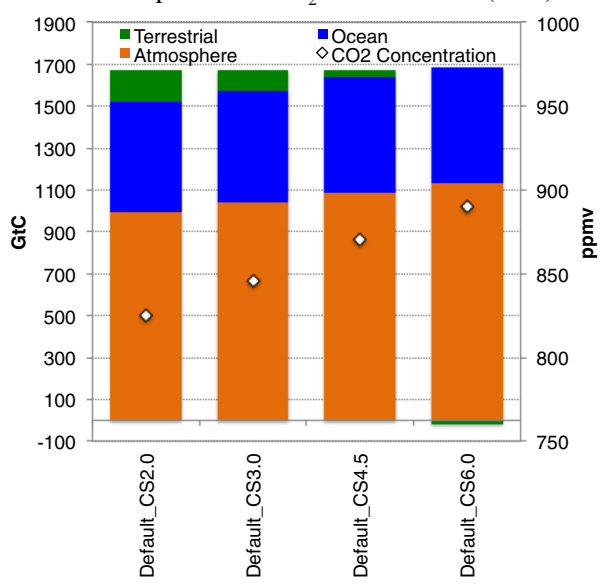

d Cumulative Carbon Uptake (POL4.5)

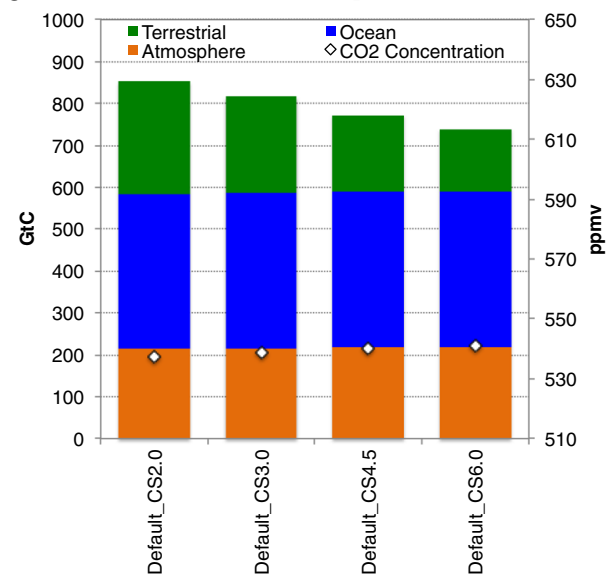

Fig. 3 Cumulative emissions (2005-2095), cumulative carbon uptake (2005-2095), and $2095 \mathrm{CO}_{2}$ concentrations in the REF and POL4.5 scenarios

the likelihood of staying below various temperature thresholds for each emissions scenario (see (Waldhoff and Fawcett 2011) for more information). While the POL3.7 scenario has a most likely GMT change in 2095 only $0.4{ }^{\circ} \mathrm{C}$ less than the POL4.5 scenario, the probability of the GMT change remaining below $2{ }^{\circ} \mathrm{C}$ is more than two times greater under the more stringent policy (39\% as compared to $17 \%$ ), while under the REF scenario, there is essentially no chance of remaining below this target. In addition, the probability of exceeding more extreme temperature thresholds, such as $4{ }^{\circ} \mathrm{C}$ or $5{ }^{\circ} \mathrm{C}$ is greatly reduced in the policy scenarios. For instance, there is a $45 \%$ chance of GMT change exceeding $4{ }^{\circ} \mathrm{C}$ in 2095 for the REF scenario. The likelihood of this more extreme temperature change is $9 \%$ and $3 \%$ for the POL 4.5 and POL 3.7 
a
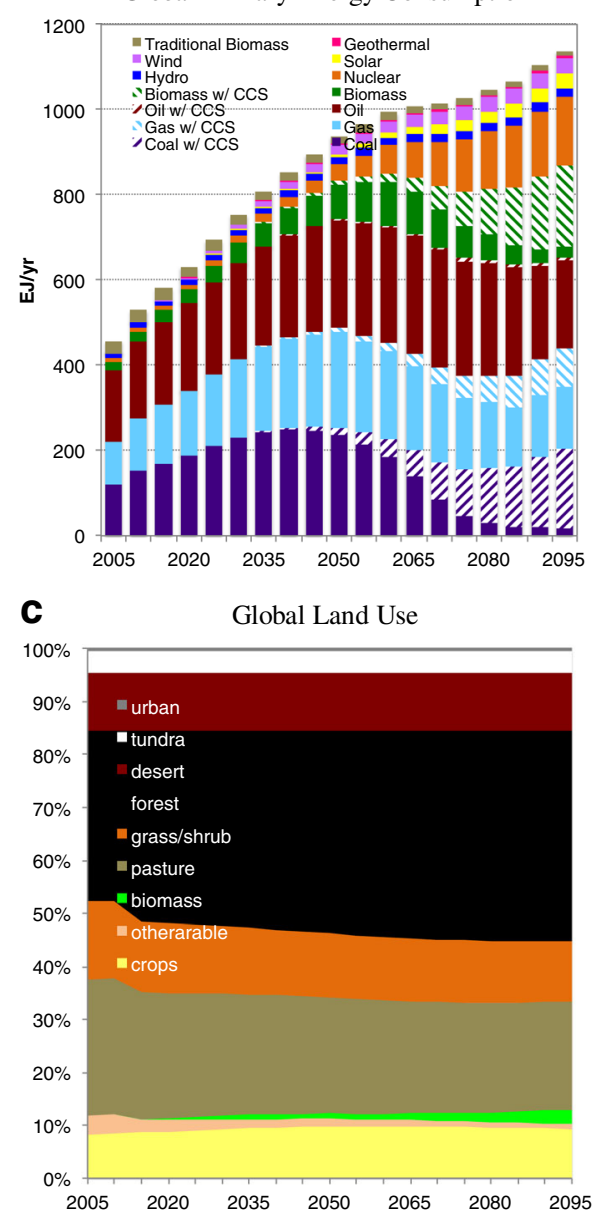

b
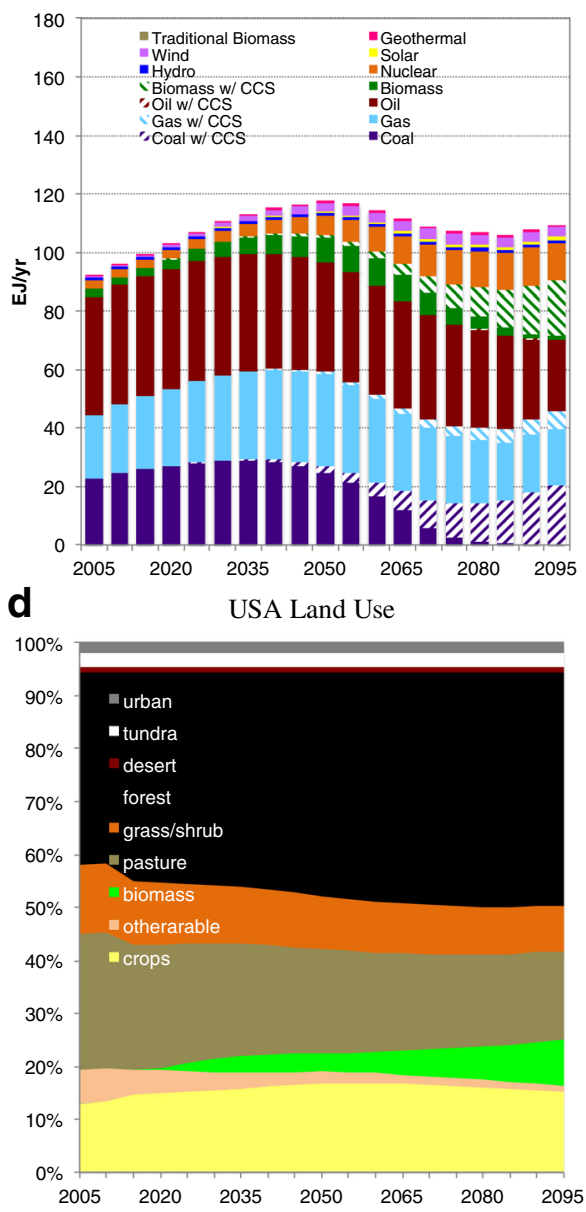

Fig. 4 Primary energy consumption and land use in the POL4.5_CS3.0 scenario

scenarios, respectively. Further, the most extreme GMT change outcomes are virtually eliminated with more stringent policy targets.

\section{Discussion}

In this paper, we examine future changes in the energy, agriculture, land, water, and climate in three policy scenarios under four different climate sensitivities. We find that without any climate action, anthropogenic emissions continue to rise throughout the coming century. These increases cause GMT to rise between $3{ }^{\circ} \mathrm{C}$ and $6{ }^{\circ} \mathrm{C}$ from 

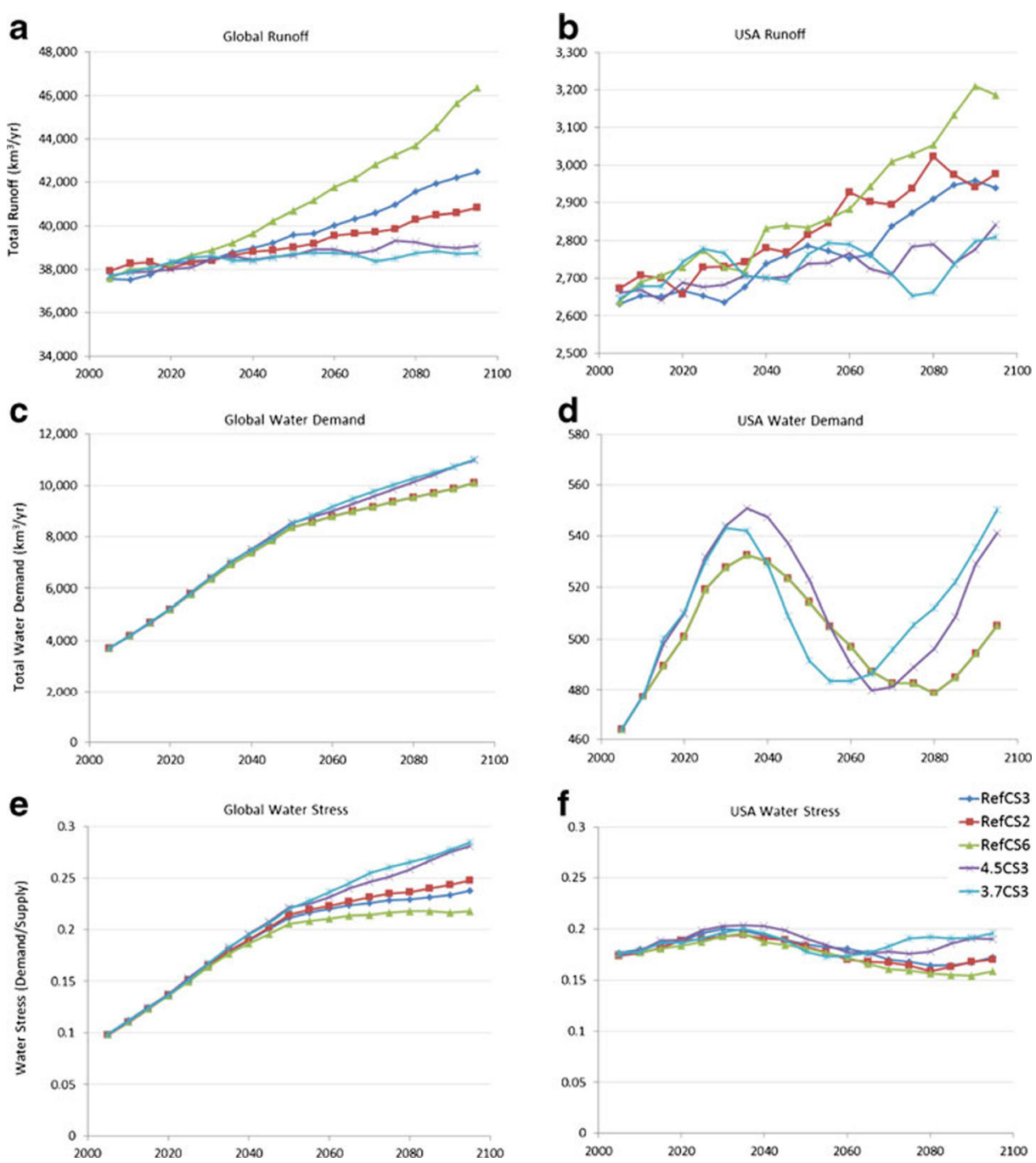

Fig. 5 Total water supply (runoff), water demand, and water stress in the REF_CS2.0, REF,_CS3.0, REF_CS6.0, POL4.3_CS3.0, and POL3.7_CS3.0 scenarios

preindustrial by 2095, depending on CS. The imposition of a carbon price reduces emissions substantially, resulting in a decrease the projected temperature rise from REF. Specifically, 2095 GMT rise ranges from $2{ }^{\circ} \mathrm{C}$ to $4{ }^{\circ} \mathrm{C}$, depending on the RF target $\left(3.7 \mathrm{~W} / \mathrm{m}^{2}\right.$ or $\left.4.5 \mathrm{~W} / \mathrm{m}^{2}\right)$ and the $\mathrm{CS}$. Importantly, climate policy increases the probability of staying below a particular temperature threshold. The chance of keeping GMT below $2{ }^{\circ} \mathrm{C}$ increases from $0 \%$ in the REF to $17 \%$ in POL4.5 and $39 \%$ in POL3.7.

Additionally, our results indicate that temperature rise affects the ability of the terrestrial system to store carbon, leading to higher $\mathrm{CO}_{2}$ concentrations for the same 
a

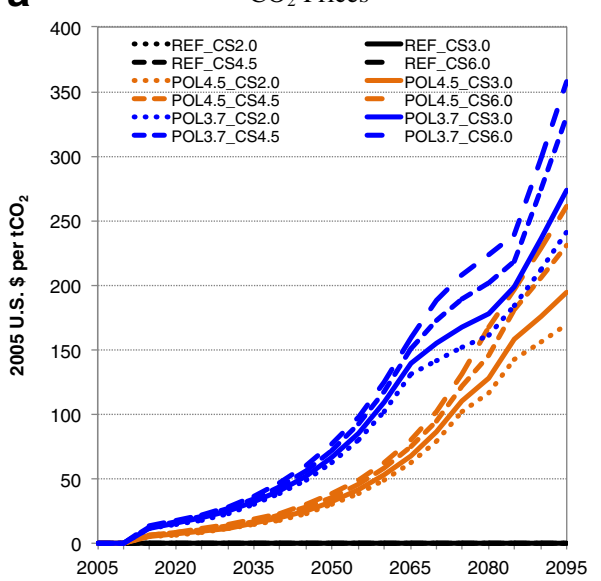

C

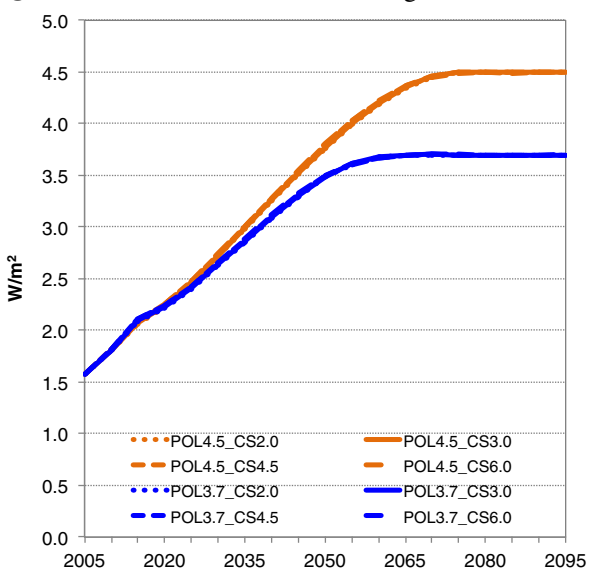

b Total Anthropogenic $\mathrm{CO}_{2}$ Emissions

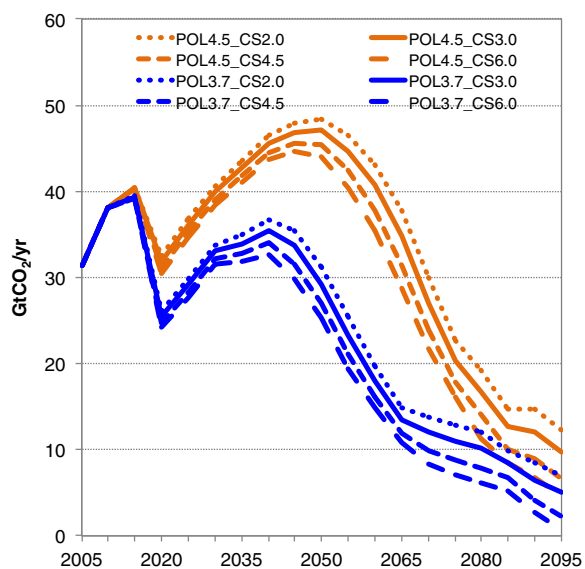

d

Global Mean Temperature Rise

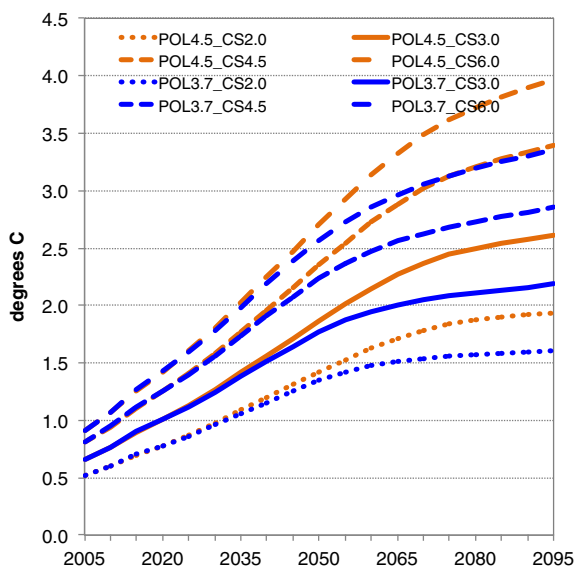

Fig. $6 \mathrm{CO}_{2}$ prices, emissions, radiative forcing, and temperature rise in the POL3.7 and POL4.5 scenarios

emissions levels under higher climate sensitivities. When a climate policy is imposed, we find that higher climate sensitivities require higher carbon prices to limit RF to the same level due to this carbon cycle feedback. This effect places additional uncertainty on outcomes when specifying a RF target (commonly defined in the literature). Such a target renders both the cost of mitigation and the expected temperature outcome uncertain, as both are dependent on the actual CS.

The analysis conducted in this paper focuses on one uncertainty within the earth system. However, many other aspects of this system are uncertain, including $\mathrm{CO}_{2}$ fertilization, climate-carbon cycle feedbacks, aerosol forcing, and ocean heat diffusion. By focusing only on uncertainty in the CS, we do not fully explore the interactions among the carbon cycle, climate, and economy. Instead, we leave a more thorough investigation of these interactions to future research. 


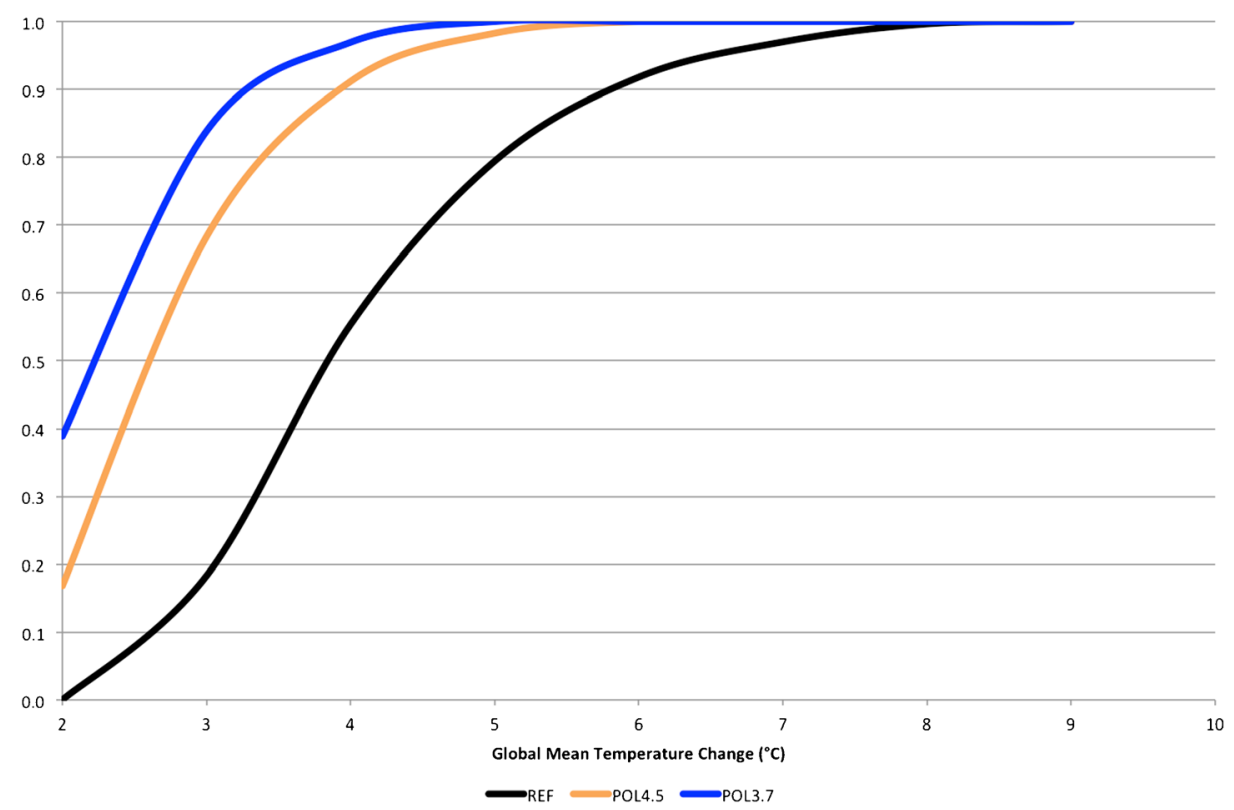

Fig. 7 Probability of remaining below various temperature thresholds under different policy scenarios

Acknowledgments The authors are grateful for support from the Environmental Protection Agency's Climate Change Division. The authors also wish to express appreciation to the Integrated Assessment Research Program in the Office of Science of the U.S. Department of Energy (DOE SC-IARP) for partially funding this research. This research used Evergreen computing resources at the Pacific Northwest National Laboratory's Joint Global Change Research Institute at the University of Maryland, which is supported by DOE SC-IARP. The views and opinions expressed in this paper are solely those of the authors, and do not necessarily reflect those of EPA or DOE.

Open Access This article is distributed under the terms of the Creative Commons Attribution License which permits any use, distribution, and reproduction in any medium, provided the original author(s) and the source are credited.

\section{References}

Bernstein P, Bigger S, Montgomery WD (2003) When cost measures contradict. Charles River Associates, Washington, DC

Bond-Lamberty B, Thomson A (2010) Temperature-associated increases in the global soil respiration record. Nature 464:579-582

Caldeira K, Jain A, Hoffert M (2003) Climate sensitivity uncertainty and the need for energy without CO2 emission. Science 299:2052-2054

Calvin K, Clarke L, Edmonds J, Eom J, Hejazi M, Kim S, Kyle P, Link R, Luckow P, Patel P (2011) GCAM Wiki Documentation. Pacific Northwest National Laboratory, Richland

Calvin K, Patel P, Fawcett A, Clarke L, Fisher-Vanden K, Edmonds J, Kim S, Sands R, Wise M (2009) The distribution and magnitude of emissions mitigation costs in climate stabilization under less than perfect international cooperation: SGM results. Energy Econ 31:S187-S197

Chaturvedi V, Hejazi M, Edmonds J, Clarke L, Kyle P, Davies E, Wise M, (2013) Climate mitigation policy implications for global irrigation water demand. Mitig Adapt Strateg Glob Change 1-19. doi:10.1007/ s11027-013-9497-4 
Clarke L, Edmonds J, Jacoby H, Pitcher H, Reilly J, Richels R (2007) CCSP Synthesis and Assessment Product 2.1a: Scenarios of Greenhouse Gas Emissions and Atmospheric Concentrations. U.S. Government Printing Office, Washington, DC

Cox P, Betts R, Jones C, Spall S, Totterdell I (2000) Acceleration of global warming due to carbon-cycle feedback in a coupled model. Nature 408:184-187

Davies E, Kyle P, Edmonds J (2013) An integrated assessment of global and regional water demands for electricity generation to 2095. Adv Water Resour 52:296-313

Edmonds J, Smith SJ (2006) The technology of two degrees. In: Schellnhuber HJ, Cramer W, Nakicenovic N, Wigley T, Yohe G (eds) Avoiding Dangerous Climate Change. Cambridge University Press, Cambridge

Friedlingstein P, Bopp L, Ciais P, Dufresne J-L, Fairhead L, LeTreut H, Monfray P, Orr J (2001) Positive feedback between future climate change and the carbon cycle. Geophys Res Lett 28:1543-1546

Friedlingstein P, Cox P, Betts R, Bopp L, von Bloh W, Brovkin V, Cadule P, Doney S, Eby M, Fung I, Bala G, John J, Jones C, Joos F, Kato T, Kawamiya M, Knorr W, Lindsay K, Matthews HD, Raddatz T, Rayner P, Reick C, Roeckner E, Schnitzler KG, Schnur R, Strassmann K, Weaver AJ, Yoshikawa C, Zeng N (2006) Climate-carbon cycle feedback analysis: results from the C4MIP model intercomparison. J Clim 19:33373353

Hegerl G, Zwiers F (2007) Understanding and attributing climate change. In: Solomon S, Qin D, Manning M, Chen Z, Marquis M, Averyt KB, Tignor M, Miller HL (eds) Climate Change 2007: The Physical Science Basis. Cambridge University Press, Cambridge and New York

Hejazi M, Edmonds J, Chaturvedi V, Davies E, Eom J (2013) Scenarios of global municipal water use demand projections over the 21st Century. Hydrol Sci J 58(3):519-538

IPCC (2007) Climate Change 2007: The Physical Science Basis. Contribution of Working Group I to the Fourth Assessment Report of the Intergovernmental Panel on Climate Change. in Solomon S, Qin D, Manning M, Chen Z, Marquis M, Averyt K, Tignor M, Miller H (eds.). Cambridge University Press, Cambridge, United Kingdom and New York, NY, USA

Johansson D (2011) Temperature stabilization, ocean heat uptake and radiative forcing overshoot profiles. Clim Chang 108:107-134

Kim S, Edmonds J, Lurz J, Smith S, Wise M (2006) The ObjECTS: Framework for integrated assessment: hybrid modeling of transportation. The Energy J 27:63-92

Kyle P, Davies E, Dooley J, Smith SJ, Clarke L, Edmonds J, Hejazi M (2013) Influence of climate change mitigation technology on global demands of water for electricity generation. Int J Greenh Gas Control 13: $112-123$

Le Quere C, Raupach MR, Canadell JG, Marland G et al (2009) Trends in the sources and sinks of carbon dioxide. Nat Geosci 2:831-836

Luderer G, Bosetti V, Jakob M, Leimbach M, Steckel J, Waisman H, Edenhofer O (2012) The economics of decarbonizing the energy system - results and insights from teh RECIPE model intercomparison. Clim Chang 114:9-37

Meehl GA, Stocker TF, Collins WD, Friedlingstein P, Gaye AT, Gregory JM, Kitoh A, Knutti R, Murphy JM, Noda A, Raper SCB, Watterson IG, Weaver AJ, Zhao Z-C (2007) Global climate projections. In: Solomon S, Qin D, Manning M, Chen Z, Marquis M, Averyt KB, Tignor M, Miller HL (eds) Climate Change 2007: The Physical Science Basis. Contribution of Working Group I to the Fourth Assessment Report of the Intergovernmental Panel on Climate Change. Cambridge University Press, Cambridge, United Kingdom and New York, NY, USA

Meinshausen M, Meinshausen N, Hare W, Raper S, Frieler K, Knutti R, Frame D, Allen M (2009) Greenhousegas emission targets for limiting global warming to $2{ }^{\circ} \mathrm{C}$. Nature $458: 1158-1162$

Montgomery WD, Smith A, Bigger S (2003) Measuring the costs of climate change policies: issues in the interpretation of common metrics. Charles River Associates, Washington, DC

Paltsev S, Monier E, Scott J, Sokolov A, Reilly J (2013, this issue) Integrated Economic and Climate Projections for Impact Assessment. Climatic Change Submitted

Randerson J, Hoffman F, Thornton P, Mahowald N, Lindsay K, Lee Y-H, Nevison C, Doney S, Bonan G, Stockli R, Covey C, Running S, Fung I (2009) Systematic assessment of terrestrial biogeochemistry in coupled climate-carbon models. Glob Chang Biol 15:2462-2484

Roe G, Baker M (2007) Why is climate sensitivity so unpredictable? Science 318:629-632

Smith SJ, Edmonds J (2006) The economic implications of carbon cycle uncertainty. Tellus 58B:586-590

Tanaka K, Kriegler E, Bruckner T, Hooss G, Knorr W, Raddatz T (2007) Aggregated Carbon Cycle, Atmospheric Chemistry, and Climate Model (ACC2) - description of the forward and inverse modes. In Meterology MPIf (ed.) Reports on Earth System Science, Hamburg, Germany

Waldhoff S, Fawcett A (2011) Can developed economies combat dangerous anthropogenic climate change without near-term reductions from developing economies? Clim Chang 107:635-641 
Waldhoff S, Martinich J, Sarofim M, DeAngelo B, McFarland J, Jantarasami L, Shouse K, Crimmins A, Li J (2013) Overview of the Special Issue: A multi-model framework to achieve consistent evaluation of climate change impacts in the United States. Clim Chang (this issue)

Wigley T, Raper S (1992) Implications for climate and sea-level of revised IPCC emissions scenarios. Nature 357:293-300

Wise M, Calvin K, Thomson A, Clarke L, Bond-Lamberty B, Sands R, Smith SJ, Janetos A, Edmonds J (2009) Implications of limiting $\mathrm{CO}_{2}$ concentrations for land use and energy. Science 324:1183-1186

Zeng N, Qian H, Munoz E, Iacono R (2004) How strong is the carbon cycle-climate feedback under global warming? Geophys Res Lett 31(20). doi:10.1029/2004GL020904 